Canadian

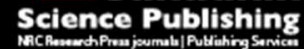

Canadian Journal of Microbiology Revue canadienne de de microbiologie

\title{
A review of techniques for detecting Huanglongbing (greening) in citrus
}

\begin{tabular}{|r|l|}
\hline Journal: & Canadian Journal of Microbiology \\
\hline Manuscript ID & cjm-2016-0022.R1 \\
\hline Danuscript Type: & Review \\
\hline Complete List of Authors: & $\begin{array}{l}\text { Arredondo Valdés, Roberto; Universidad Autonoma Agraria Antonio Narro } \\
\text { Delgado Ortiz, Juan; Universidad Autonoma Agraria Antonio Narro } \\
\text { Beltrán Beache, Mariana; Universidad Autonoma Agraria Antonio Narro } \\
\text { Anguiano Cabello, Julia; Universidad Autonoma Agraria Antonio Narro } \\
\text { Cerna Chavez, Ernesto; Universidad Autonoma Agraria Antonio Narro } \\
\text { Rodriguez Pagaza, Yolanda; Universidad Autonoma Agraria Antonio Narro } \\
\text { OCHOA, YISA; UNIVERSIDAD AUTTONOMA AGRARIA ANTONIO NARRO, } \\
\text { PARASITOLOGIA }\end{array}$ \\
\hline Keyword: & HLB, Detection, Trees, Monitoring, Health \\
\hline \multicolumn{2}{|c}{} \\
\hline
\end{tabular}




\section{A review of techniques for detecting Huanglongbing (greening) in citrus}

Roberto Arredondo Valdés ${ }^{1}$; Juan C Delgado Ortiz ${ }^{1}$; Mariana Beltrán Beache ${ }^{1}$; Julia Anguiano Cabello ${ }^{1}$, Ernesto Cerna Chávez ${ }^{2}$; Yolanda Rodríguez Pagaza ${ }^{3}$; Yisa M. Ochoa Fuentes $^{2}$

1 Post grade student, Universidad Autónoma Agraria Antonio Narro. Department of Agricultural Parasitology, Buenavista, Saltillo, Coahuila, Mexico CP 25315. e-mail: robqf@gmail.com,_ julia_c92@hotmail.com,_moe_788@hotmail.com, beltranmariana89@gmail.com

${ }^{2}$ Universidad Autónoma Agraria Antonio Narro. Department of Agricultural Parasitology, Buenavista, Saltillo, Coahuila, Mexico CP 25315. ${ }^{2}$ e-mail: jabaly1@yahoo.com, yisa8a@yahoo.com

${ }^{3}$ Catedrática CONACYT-Universidad Autónoma Agraria Antonio Narro. Department of Agricultural Parasitology, Buenavista, Saltillo, Coahuila, Mexico CP 25315. e-mail: yrodriguezpa@conacyt.mx

Corresponding author; Yisa Ochoa yisa8a@yahoo.com 


\begin{abstract}
Huanglongbing (HLB) is the most destructive disease of citrus worldwide. Monitoring of health and detection of diseases in trees is critical for sustainable agriculture. HLB symptoms are virtually the same wherever the disease occurs. The disease is caused by Candidatus Liberibacter spp., vectored by the psyllids Diaphorina citri Kuwayama and Trioza erytreae. Electron microscopic technique was the first method for HLB detection. Nowadays, scientists are working on the development of new techniques for a rapid HLB detection as there is no sensor commercially accessible for real-time assessment of health conditions in trees. Currently, exploration is the most widely used mechanism for monitoring HLB, which is an expensive, labor-intensive and time-consuming process. Molecular techniques such as polymerase chain reaction are used for the identification of HLB disease, which requires detailed sampling and processing procedures. Furthermore, investigations are ongoing in spectroscopic and imaging techniques, profiling of plant volatile organic compounds and isothermal amplification. This study recognizes the need for developing a rapid, costeffective, and reliable health monitoring sensor that would facilitate advancements in HLB disease detection. This paper compares the benefits and limitations of these potential methods for HLB detection.
\end{abstract}

Keywords: HLB, Detection, Trees, Monitoring, Health

\title{
Introduction
}

Citrus production is one of the most important economic agricultural activities in the world. According to the Food and Agriculture Organization (FAO 2014), approximately 122 millions of tons of citrus fruits are produced annually, corresponding to roughly US \$17 billion from the sale of juices and fresh fruit worldwide in 2008. Economic losses in citrus 
production have occurred in recent years due to diseases such as citrus greening disease or Huanglongbing (HLB), which has become one of the greatest challenges for citrus growers across the world (Cevallos-Cevallos et al. 2012), because it reduces fruit yield and quality and severely debilitates citrus trees (Qureshi and Stansly 2009). The world's largest citrus producers, Brazil, China, India, Mexico and the United States are especially threatened by the HLB (Do Brasil Cardinali et al. 2012; FAOSTAT 2009). HLB has been associated with Gram negative bacteria, obligate parasite, phloem-limited $\alpha$-protobacterium, Candidatus Liberibacter spp. (Gottwald 2010). The genus Candidatus Liberibacter has three known species: Candidatus Liberibacter asiaticus (Las), Candidatus Liberibacter africanus (Laf) and Candidatus Liberibacter americanus (Lam). HLB can be transmitted by grafting from citrus to citrus and by dodder to periwinkle. Trioza erytreae and Diaphorina citri psyllids are natural vectors (Bové 2006). Early disease detection relies primarily on scouting for disease symptoms in the field, such as yellow shoots, blotchy mottle leaf and lopsided fruit with green color remaining on the stylar end, aborted seeds and high levels of starch in the leaves (Gonzalez et al. 2009) Nevertheless visual inspection is one of the most applied methods to diagnose citrus greening, this approach is highly influenced by subjective interpretation, and diagnostic errors can be higher than 30\% (Pereira et al. 2011) and diagnosis may be worsened by other biotic and/or abiotic plant health related problems (Lin et al. 2010). HLB symptoms can be confused with diseases as Citrus Tristeza Closterovirus (CTV), Phytophthora infection, citrus blight and certain nutrient deficiencies (Shokrollah et al. 2011). Methods such as electron microscopy, serology, DNA probes, enzymatic assay, enzymelinked immunosorbent assays (ELISA), conventional polymerase chain reaction (PCR) (Yamamoto et al. 2008) and quantitative PCR (qPCR) are used for the diagnosis and confirmation of HLB (Kogenaru et al. 2014). X-ray fluorescence (XRF) and laser-induced breakdown spectroscopy (LIBS) combined with chemometric strategies are used to 
successfully predict the condition of orchard plants infected with Candidatus Liberibacter spp. (Pereira and Milori 2010). Fourier transform infrared (FTIR) spectroscopy has also been used for the diagnosis of diseased citrus plants, and mid-infrared spectroscopy has been used to study citrus greening infection; however, except for LIBS method, these studies did not provide early diagnosis. Early detection and quarantine of Las-infected trees are important management strategies used to prevent HLB from invading HLB-free citrus producing regions (Kogenaru et al. 2014). In this paper, a review of current diagnostic techniques for HLB disease performed worldwide is described, because an early diagnosis and differentiation of Candidatus Liberibacter spp. is critical in reducing the local and via international trade spread and devastation of this disease, as well as minimizing the economic impact of potential false positive diagnoses.

\section{Microscopic techniques for Huanglongbing disease detection}

In 1970 Electron microscopy was the first laboratory technique used by Lafleche and Bove (1970) for the identification and confirmation of HLB (Bové 2006); however in citrus trees with HLB, the symptoms are difficult to identify. Yellow shoots, leaf blotchy mottle, and lopsided fruits with color inversion and aborted seeds are all characteristic, but they do not always occur together in the same tree (Cevallos-Cevallos et al. 2009; Folimonova et al. 2010); they can be distorted or masked by symptoms of other diseases or in some cases, induced by conditions unrelated to HLB (Cevallos-Cevallos et al. 2009). In 2009 Cevallos-Cevallos described techniques such as Light microscopy (LM) and transmission electron microscopy (TEM), which were used on leaves, petioles, stems, bark and roots that were sampled from HLB-affected and control Valencia trees. The samples were fixed in 3\% glutaraldehyde, $0.1 \mathrm{M}$ potassium phosphate buffer, $\mathrm{pH} 7.2$, for $4 \mathrm{~h}$ at room temperature and then overnight in the refrigerator. They were then washed in the same buffer and post-fixed $4 \mathrm{~h}$ at room temperature in $2 \%$ osmium tetroxide in the above buffer. The 
samples were then dehydrated in acetone series and embedded in Spurr's resin. For light microscopy, $1 \mathrm{~mm}$ sections were cut with glass knives and stained with methylene blue/azure A, post-stained in basic fuchsin. Light micrographs were taken on a Leitz Laborlux S compound microscope (Germany) with a Canon Powershot S31S digital camera (Tokyo, Japan). For TEM, the same blocks were thin sectioned (90-100 nm) with a diamond knife, collected on 200 mesh copper grids and stained with $2 \%$ uranyl acetate (aq.) and poststained with lead citrate. Micrographs were made with an AMT (Advanced Microscopy Techniques Corp., Danvers, MA) digital camera on a Morgagni 268 (FEI Company, Hillsboro, OR) transmission electron microscope (Cevallos-Cevallos et al. 2009). In another way Svetlana and Diann in 2010, conducted microscopy studies in cooperation with FEI Company (The Netherlands), using a Morgani 268 TEM. Leaf and petiole samples were collected from trees induced with HLB disease; to prepare these samples for TEM, a routine fixation procedure was used in which they were fixed with the same technique used by Cevallos-Cevallos in 2009, but the difference is that Svetlana and Diann used resin for 3 days, then samples $(1 \mu \mathrm{m})$ were taken for light microscopy observations. Sections of $100 \mathrm{~nm}$ in size were mounted on 200-mesh formvar-coated copper grids and stained with $2 \%$ uranyl acetate (aq.) and lead citrate. The thin sections were further examined with a Morgagni 268 transmission electron microscope.

The microscopic techniques in different investigations are analogous; examinations of the disease-affected tissues using TEM revealed that the pathogenic bacterium possesses a cell wall of the Gram-negative type and exclusively resides within the sieve tubes of infected citrus trees (Svetlana and Diann 2010). These properties of the bacterium were used as a basis for the detection of HLB by electron microscopy, which had been the only reliable diagnostic technique for a number of years prior to the development of detection methods based on DNA hybridization and PCR. 


\section{Molecular techniques for Huanglongbing disease detection}

In recent years, molecular techniques of plant disease detection have been well established. The sensitivity of molecular techniques refers to the minimum amount of microorganism that can be identified in the sample. It is reported that the sensitivity of molecular techniques for detecting bacteria ranged from 10 to $10^{6}$ colony forming units/mL (Sankaran et al. 2010). The commonly used molecular techniques for disease detection are ELISA, PCR and qPCR, other molecular techniques include immunofluorescence (IF), flow cytometry, fluorescence in situ hybridization (FISH), and DNA microarrays (Sankaran et al. 2010).

Huanglongbing is one of bacterium which has yet to be cultivated in vitro, consequently, the pathogen was given a provisional Candidatus status in nomenclature; currently three species of the pathogen are recognized from trees with HLB disease based on the amplification of a 1160 bp fragment of the $16 \mathrm{~S}$ rDNA sequence of a Candidatus Liberibacter spp: Las, Laf, and Lam (Kim and Wang 2009; Bové 2006; Li and Levy 2006; Pietersen et al. 2014). Two PCR systems have been used in HLB disease. The first is based on 16S rDNA sequence, using many sequences of primers and probes (Fujikawa and Iwanami 2012). OI1/OI2c is able to amplify the rDNA Las and Laf species (Teixeira et al. 2005a). When the two Ca. Liberibacter spp are known or supposed to be present in any country, it is desirable to use the two forward primers, OI1 + OA1, and the common reverse OI2c primer in the same PCR mixture (Bové 2006). Sequence analysis shows that the rDNA amplified from Las has one $X b a 1$ restriction site, and yields, upon $X b a 1$ treatment, two fragments of sizes $520 \mathrm{bp}$ and 640 bp., respectively. The rDNA amplified from Laf has an additional restriction site, and yields three fragments of $520 \mathrm{bp}, 506 \mathrm{bp}$, and $130 \mathrm{bp}$. (Jagoueix et al., 1996; Teixeira et 
al., 2005a). The second PCR is centered on the nusG-rplKoperon region (A2/ J5 and MHO353/MHO354) (Fujikawa and Iwanami 2012). The intergenic region between genes $r p l \mathrm{~A}$ and $r p l \mathrm{~J}$ is $34 \mathrm{bp}$ larger in Las compared to Laf. With forward primer f-rplA2, selected in the $r p l$ A gene, and reverse primer r-rplJ5 from the $r p l J$ gene, a 703 bp DNA is amplified from Las, while a 669 bp DNA is obtained with Laf, if both $C a$. Liberibacter spp. are present in the same sample. Amplification of the two DNAs is obtained, and upon agarose gel electrophoresis, two DNA bands are seen, the upper (703 bp) corresponding to Las, and the lower (669 bp) to Laf(Bové 2006). A third Ca. Liberibacter specie was identified in Sao Paulo, Brazil by the nusG-rplKAJL-rpoBC gene clusters of Las and Laf, which were obtained and sequenced (Teixeira et al. 2005a,b).The same gene cluster has recently been obtained from Lam. additional $C a$. Liberibacter genes, including the omp gene, have been isolated by using Random Amplified Polymorphic DNA (RAPD). The omp gene was used to study the genetic variability of Las (Teixeira et al. 2008). Currently, quantitative PCR has become the preferred detection method of $\mathrm{Ca}$. Liberibacter spp. (Li et al. 2009). Compared to conventional PCR, qPCR offers both sensitive and rapid detection of these bacteria. qPCR is reported to increase the sensitivity for $\mathrm{Ca}$. Liberibacter spp. detection by 10 times relative to nested PCR, and 100 to 1000 times relative to conventional PCR for these bacteria (Morgan et al. 2012). qPCR methods target genes with low copy number: three copy $16 \mathrm{~S}$ rDNA, single copy b-operon or single copy elongation factor Ts (EF-Ts). The reported low sill limits of qPCR are around ten gene copies for $16 \mathrm{~S}$ rDNA and b-operon procedures (Teixeira et al. 2008), and single gene copy for the elongation factor Ts (single closed tube with dual sets of primers; (Morgan et al. 2012). In another way, Kim and Wang (2009) compared the detection of HLB with different qPCR based methods to primer probes targeting either $16 \mathrm{~S}$ rDNA or b-operon DNA. The $16 \mathrm{~S}$ rDNA copy number of Las was estimated to be three times of that of the b-operon 
region, consequently allowing their detection. Quantitative Reverse Transcriptase PCR (qRTPCR) showed that 16 rRNA averaged 7.83 times more than $16 \mathrm{~S}$ rDNA for equal samples. Dilution analysis also indicates that qRT-PCR targeting 16S rRNA is 10 time more sensitive than qPCR targeting $16 \mathrm{~S}$ rDNA, thus qRT-PCR was able to increase the sensitivity of detection by targeting 16S rRNA. On June of 2013, Nageswara-Rao et al. made an effort to develop a variety of candidate gene markers specific to Las for early detection of HLB disease; the effectiveness of the primer pairs developed were also tested for cross-specie amplification, if any, against the other two HLB-cousing species Laf and Lam. Teixeira et al. (2005a) reported three primers pairs successfully developed from thirty-two different genespecific primer pairs, across Las genome. The possibility of these primer pairs for crossgenome amplification across Laf and Lam were tested and their conclusions of the applicability for detection and differentiation of Candidatus Liberibacter spp. was discussed. A list of specific primer used in conventional PCR and qPCR to identify $C a$. Liberibacter spp., is reported in Table 1.

In another way DNA dot and Southern hybridization was employed by Hung et al. (1999). In this study, DNA cloning methods were developed and used to detect HLB in infected citrus hosts. One of the clones containing a $0.24 \mathrm{~kb}$ HLB-specific DNA fragments was labeled with biotinylated nucleotides by a PCR-labeling technique. A dot hybridization assay with a biotin-labeled DNA probe has been successfully used for detecting HLB in various citrus hosts including mandarins, tangors, sweet oranges and pummels. This probe could specifically react with all HLB strains from several Asian countries, but not with those from South Africa. The developed probe is specified with sensitivity enough to detect minute levels of HLB infection and, therefore, can be used in quarantine of the Asian Greening disease (Hung et al. 1999). 
Meanwhile, the first study of transcriptional profiling in response to Candidatlus Liberibacter spp. infection using microarray technology was developed by Albrecht and Bowman in 2008 . Microarray technology has been used in several studies of bacterial plant diseases such as bacterial blight (Li et al. 2006) and bacterial spot (Gibly et al. 2004), as well as viral, fungal, and other diseases (Espinoza et al. 2007; Panthee et al. 2007). Albrecht and Bowman (2008) investigated the gene expression of sweet orange plants (Citrus sinensis L. Osbeck) in response to infection with Las in comparison with non-infected healthy plants using the Affymetrix GeneChip ${ }^{\circledR}$ citrus genome microarray. Due to the compatibility of the interaction, significant transcriptional changes were expected to happen between genes associated with cellular modifications caused by infection processes or involved in general defense and stress-responses. Citrus genome array provides new insights into the molecular basis of citrus response to this pathogen. Of the more than 33,000 probe sets on the microarray, 21,067 were expressed in the leaves, of which 279 and 515 were differentially expressed (false-discovery rate $($ FDR) $\leq 0.05) 5-9$ and $13-17$ weeks after inoculation, respectively. Outstanding was the pathogen-induced accumulation of transcripts for a phloem-specific lectin PP2-like protein. Transcriptional changes and their relation to disease symptom development are discussed (Albrecht and Bowman 2008).

Although there are laboratory-based PCR methods that can accurately detect HLB, there is a need for a sensing or screening system that would provide reliable detection of citrus greening symptoms in real-time and under field conditions. Since PCR technique is expensive and time-consuming (Hawkins et al. 2010), having a prescreening technique that can detect the infected trees will reduce the demand for exploration. Also it will reduce the quantity of samples for PCR testing which could results in lower disease management costs and more effective disease recognition.

\section{Spectroscopic and imaging techniques for Huanglongbing disease detection}


The most accurate HLB diagnosis involves PCR (Hansen et al. 2008), but the identification of infected trees and sampling of leaves is time consuming. Moreover, the average accuracy achieved in visually inspecting and identifying infected trees by scouts is reported to be between $47 \%$ and $59 \%$ (Futch et al. 2009). Specific regions in the electromagnetic spectra have been found to provide information about the physiological stress in plants, and consequently, diseased plants usually exhibit different spectral signature than non-stressed healthy plants in those specific ranges. The spectral reflectance from the tree canopy in the visible and infrared regions of the electromagnetic spectra can be used as an indication of plant stress (Sankaran et al.,2010). Differences in the spectral reflectance of healthy and diseased plants can be seen in the visible-infrared region (Purcell et al. 2009). Spectroscopy in the range of visible and near infrared has been investigated for disease detection in a great variety of crops since it is a rapid and non-destructive tool that can be used in real time crop assessment under field conditions (Sankaran et al.2010). For example, Naidu et al. (2009) recognized viral infection (leafroll) in grapevines (Vitis vinifera L.) under field conditions using leaf spectral response from field portable spectrometer equipped with a leafprobe. Hyperspectral reflectance in the range of 350-2500 nm was employed by Delalieux et al. (2007) to detect apple scab (Venturia inaequalis). The study concluded that the features along two spectral ranges in near infrared (1350-1750 nm and 2200-2500 nm) showed higher performance in the ordering of infected and healthy leaves at early stages. Both, the spectral regions in the range $580-660 \mathrm{~nm}$ and $688-715 \mathrm{~nm}$ showed better classification power for developed stages of infection.

Sankaran and Ehsani (2011) showed the evaluation of spectral features extracted from visible-near infrared Spectra spectroradiometer for their potential to detect citrus greening disease and did an effort to lower the cost of the optical sensor while maintaining their performance. Sankaran et al. defined spectral features: (i) spectral reflectance bands and (ii) 
vegetation indices (VIs), which were derived from 350-2,500 nm spectral reflectance data using two feature extraction methods: stepwise discriminant analysis and stepwise regression analysis. Following the selection of spectral features, the features were assessed using two classifiers: quadratic discriminant analysis (QDA) and soft independent modeling of classification analogies (SIMCA) to determine the overall and individual classification accuracies. The classification results indicated that both spectral features (spectral bands and VIs) yielded good overall (higher than $80 \%$ ) and healthy class (higher than $85 \%$ ) classification accuracies using the QDA-based algorithm. The SIMCA-based algorithm yielded good average citrus greening classification accuracy (higher than 83\%) using selected spectral features. Sankaran and Ehsani (2011) demonstrated the applicability of utilizing spectral features for detection of greening in citrus, thus laying the foundation for the development of new projects, protocols and tools for rapid and early HLB disease. For example, Mishra et al. (2011) focused on a low-cost, multi-band active optical sensor study to evaluate the identification of HLB-infected trees from the healthy trees. The sensor measured reflectance of tree canopy in four bands: two visible bands at $570 \mathrm{~nm}$ and $670 \mathrm{~nm}$, and two near infrared bands at $870 \mathrm{~nm}$ and $970 \mathrm{~nm}$. Extensive field measurements were conducted using this sensor. Analysis of the data showed that due to the large variability in the data, it was not possible to discriminate healthy from infected trees based on a single measurement from a tree; however, using multiple measurements from a tree it was possible to achieve high classification accuracies. With five measurements from each tree, classification methods such as k-nearest neighbors, support vector machines, and decision trees resulted in classification errors of less than 5\%. Mishra et al. results demonstrated and confirmed the potential of a multi-band active optical sensor for detecting HLB-infected citrus trees under field conditions. In another way, Garcia-Ruiz et al. (2013) presented a new methodology of high-resolution aerial imaging for HLB detection using a low-cost, low- 
altitude remote sensing multi-rotor unmanned aerial vehicle (UAV). A multi-band imaging sensor was attached to a UAV that is capable of acquiring aerial images at desired resolution by adjusting the flying altitude. Moreover, Garcia-Ruiz et al., obtained results using UAVbased sensors that were compared with a similar imaging system (aircraft-based sensors) with lower spatial resolution. Data was comprised from six spectral bands (from 530 to $900 \mathrm{~nm}$ ) and seven vegetation indices derived from the selected bands. Garcia-Ruiz et al. used stepwise regression analysis to extract relevant features from UAV-based and aircraft-based spectral images. At spatial resolutions, $710 \mathrm{~nm}$ reflectance and NIR-R index values were found to be significantly different between healthy and HLB-infected trees. During classification studies, accuracies in the range of $67-85 \%$ and false negatives from $7 \%$ to $32 \%$ were acquired from UAV-based data, while corresponding values were $61-74 \%$ and $28-45 \%$ with aircraft based data. Among the tested classification algorithms, support vector machine (SVM) with kernel resulted in better performance than other methods such as SVM (linear), linear discriminant analysis and quadratic discriminant analysis. Thus, high-resolution aerial sensing has good prospects for the detection of HLB-infected trees.

Meanwhile, Pourreza et al. (2014) studied a less expensive HLB detection based on particular symptoms, such as starch accumulation in the citrus leaf. The ability of narrow-band imaging and polarizing filters in detecting starch accumulation in symptomatic citrus leaf was evaluated in this study. A custom-made image acquisition system was developed for this purpose in which leaf samples were illuminated with polarized light using narrow-band highpower LEDs at $400 \mathrm{~nm}$ and $591 \mathrm{~nm}$, and the reflectance was measured by two monochrome cameras. Two polarizing filters were mounted in perpendicular directions in front of the cameras so that each camera acquired an image with reflected light in only one direction (parallel or perpendicular to the illumination polarization). The results of this study showed that the starch accumulation in HLB-symptomatic leaves rotated the polarization planar of 
light at $591 \mathrm{~nm}$, and this property can be effectively used in a fast and inexpensive HLB detection system. Based on the same property of starch accumulation in citrus leaf, developed a sensor that includes a highly sensitive monochrome camera, narrow band high power LEDs, and polarizing filters. The sensor was first tested and calibrated in a simulated field condition in a laboratory. Then, it was tested in a citrus grove Two simple image descriptors; mean and standard deviation of gray values, were used for the purpose of classification. The results showed that the sensor clearly highlighted the starch accumulation in the HLBinfected leaf and differentiated it from visually analogous symptoms of zinc deficiency (Pourreza et al. 2015).

Aksenov et al (2014) developed a method of disease detection based on chemical analysis of released volatile organic compounds (VOCs) that emanate from infected trees. They found that the biomarkers "fingerprint" is specific to the causal pathogen and could be interpreted using analytical methods such as gas chromatography/mass spectrometry (GC/MS) and gas chromatography/differential mobility spectrometry (GC/DMS). This VOC-based disease detection method has a high accuracy of $\sim 90 \%$ throughout the year, approaching $100 \%$ under optimal testing conditions, even at very early stages of infection where other methods are not adequate. Detecting early infection based on VOCs precedes visual symptoms and DNAbased detection techniques (real-time polymerase chain reaction, RT-PCR) and can be performed at a substantially lower cost and with rapid field deployment.

The development of techniques for fast detection spectroscopic should continue to develop, mainly focused on lower costs of equipment and rapid detection to reduce false positive results

\section{Profiling of plant volatile organic compounds for disease detection}


Disease symptom development in HLB-affected plants is associated with starch accumulation in the leaf tissue, a phenomenon which is sometimes used as a diagnostic tool, though it is also observed in response to nutritional deficiencies and viral infection. Changes in transcript levels were therefore expected to occur within the group of genes associated with carbohydrate metabolism, specifically starch synthesis (Albrecht and Bowman 2008). Metabolomics camp is a developing field of analytical chemistry focused on the identification of metabolites. Usually employed in pharmaceutical applications, metabolomics has become a powerful tool in agriculture and food science (Gibney et al. 2005; Cevallos-Cevallos et al. 2009) and has been used to characterize metabolic changes in plants after biotic and abiotic stresses, as well as biotic contamination of foods (Peluffo et al. 2010). Metabolomics techniques have been able to identify changes in the metabolite profile of different citrus varieties (Cevallos-Cevallos et al. 2012), including those affected by HLB (Cevallos-Cevallos et al. 2011). In 2012 Cevallos-Cevallos et al. conducted a study to determine GC-MS-based metabolomics differences between two citrus varieties that are sensitive to HLB ('Madam Vinous' sweet orange (MV) and 'Duncan' grapefruit (DG)) and two tolerant citrus varieties ('Carrizo citrange' (CAR) and 'Poncirus trifoliata' (TR)). Cevallos-Cevallos et al. also monitored metabolomics changes occurring during HLB infection of sensitive varieties as a first step towards understanding the HLB tolerance mechanism of citrus. The gas chromatograph (GC) used in this experiment was model HP5890 coupled to an HP5971 series mass spectrometer (MS) from Hewlett Packard, (Santa Clara, CA). Chromatogram analysis was completed using HP ChemStation software (Cevallos-Cevallos et al. 2012); Cevallos-Cevallos et al. found 61 compounds with signalto-noise ratios of at least 3 that were detected by GC-MS. Higher levels of the amino acids Lproline, L-serine, and L-aspartic acid, as well as the organic acids butanedioic and tetradecanoic acid, and accumulation of galactose in healthy plants 
were characteristic of the most sensitive variety MV. Only galactose was significantly higher in DG when compared to the tolerant varieties TR and CAR. The tolerant varieties showed higher levels of L-glycine and mannose when compared to sensitive varieties MV and DG.

Profiling of the sensitive varieties MV and DG over a 20-week period after inoculation of those with the HLB-containing material revealed strong responses of metabolites to HLB infection, which differed from the response of the tolerant varieties. Significant changes of the L-threonine level in leaves from old mature flushes and L-serine, L-threonine, scylloinositol, hexadecanoic acid, and mannose in leaves from young developing tints were observed in MV. Significant variations in myo-inositol in old flushes and L-proline, indole, and xylose in new flushes were detected in DG (Cevallos-Cevallos et al. 2012). Results were confirmed and compared with PCR, showing that it is necessary to continue further studies to better understand the metabolic profile of the HLB disease.

\section{Isothermal amplification combined with a lateral flow dipstick for rapid and sensitive detection of Candidatus Liberibacter.}

A modern DNA amplification method known as Loop Mediated Isothermal Amplification (LAMP) was adjusted for the detection of Las by Rigano et al. (2014). This methodology was combined with a Lateral Flow Dipstick (LFD) device for visual recognition of the resulting amplicons, eliminating the need for gel electrophoresis. Rigano et al. assay was highly specific for the targeted bacterium. No cross-reaction was observed with DNA from any of the other phytopathogenic bacteria or fungi assayed. By serially diluting purified DNA from an infected plant, the sensitivity of the assay was found to be 10 picograms. This sensitivity level was verified to be similar to the values obtained running a real time PCR in parallel. This methodology was able to detect Las from different kinds of samples including infected citrus plants and psyllids. Rigano et al. Results indicated that the methodology 
constituted a step forward in the development of new tools for the management, control and eradication of this destructive citrus disease. LAMP is based on the principle of autocycling strand displacement DNA synthesis performed by Bst DNA polymerase, for the detection of a specific DNA sequence (Notomi et al. 2000). The technique uses four to six primers that recognize six to eight regions of the target DNA and provides very high specificity (Nagamine et al.2002). Amplification can be carried out in a simple and inexpensive device like a water bath at temperatures between 60 to $65^{\circ} \mathrm{C}$. LAMP produces large amounts of DNA (Notomi et al.2000) and shows high tolerance to biological contaminants (Kaneko et al. 2007), thereby simplifying sample preparation. Although LAMP products can be detected by gel electrophoresis, this procedure reduces the suitability for field applications. Rigano et al. (2014) assay focused on the detection of the DNA sequence of the $t u f B-s e c E-n u s G-r p l K A J L-r p o B$ gene cluster present in the microorganism.

The analysis of the amplification products was done by gel electrophoresis or dot-blotting of the amplification products on a nylon membrane followed by staining with Mupid Blue, methods that are not compatible with field applications. The study targets a hypothetical protein-coding sequence present in the Las genome for the detection of this pathogen. To overcome the limitations associated with gel electrophoresis in the investigation, Rignano et al. (2014) coupled the LAMP amplification with a Lateral Flow Dipstick (LFD), which permits an accurate and straightforward detection of LAMP amplicons, eliminating the need of complex equipment and data analysis. Using LAMP and LFD technologies defines the development of an original molecular diagnostic tool for the detection of Las.

\section{Conclusions}

This paper reviewed and summarized some of the techniques that have been used for HLB disease detection. The five major categories for HLB detection disease are: microscopic, 
molecular, spectroscopic, profiling of plant volatile organic compounds and isothermal amplification combined with lateral flow dipstick techniques. The microscopic techniques includes light microscopic (LM) and transmission electron microscopic (TEM). Molecular techniques include conventional PCR (PCR), quantitative-PCR (qPCR), quantitative Reverse Transcriptase-PCR (qRT-PCR), random amplified polymorphic-DNA (RAPD) and microarrays. Spectroscopic and imaging techniques utilize visible and near infrared spectroscopic in the design of new tools and optical sensors for the treetops. Profiling of plant volatile organic compounds currently employs gas chromatography - mass spectrometer (GC-MS). The most recent technique in 2014 for detection HLB disease could be the isothermal amplification, which combines loop mediated isothermal amplification (LAMP) with lateral flow dipstick (LFD). This review suggests that these methods of HLB disease detection show a good potential to detect plant diseases accurately. Nevertheless it is necessary for the scientific community to continue to expand the effectiveness of the techniques and generate new research in the management and control of the disease, and thus achieve lower economic losses worldwide.

\section{References}

Aksenov, A., Pasamontes, A., Peirano, D. J., Zhao, W., Dandekar, A. M., Fiehn, O., Ehsani, R., Davis, C. E. (2014). Detection of Huanglongbing disease using differential mobility spectrometry. Analytical chemistry. dx.doi.org/10.1021/ac403469y| Anal. Chem. 2014, 86, $2481-24882483$.

Albrecht, U., \& Bowman, K. (2008). Gene expression in Citrus sinensis (L.) Osbeck following infection with the bacterial pathogen Candidatus Liberibacter asiaticus causing Huanglongbing in Florida. Plant Science, 17, 291-306. 
Bové, J.M. (2006). Huanglongbing: a destructive, newly-emerging, century-old disease of citrus. Journal of Plant Pathology, 88 (1), 7-37.

Cardinali, M.C.B., Boas, P.R.V., Milori, D.M.B.P., Ferreira, E.J., Silva, M.F., Machado, M.A., Bellete, B.S., Silva, M.F.D.G.F. (2012). Infrared spectroscopy: A potential tool in huanglongbing and citrus variegated chlorosis diagnosis. Talanta 91, 1-6.

Cevallos-Cevallos, J.M., Futch, D.B., Shilts,T., Folimonova, S.Y., \& Reyes-De-Corcuera, J.I. (2012). GC-MS metabolomics differentiation of selected citrus varieties with different sensitivity to citrus huanglongbing. Plant Physiology and Biochemistry, 53, 69:76.

Cevallos-Cevallos, J.M., Garcia-Torres, T., Etxeberria, E., \& Reyes-De-Corcuera, J.I. (2011). GC-MS analysis of headspace and liquid extracts for metabolomic differentiation of citrus huanglongbing and zinc deficiency in leaves of 'Valencia' sweet orange from commercial groves. Phytochem. Anal, 22,236-246.

Cevallos-Cevallos, J.M., Reyes-De-Corcuera, J., Etxeberria, E., Danyluk, M., \& Rodrick, G. (2009). Metabolomics in food science: a review. Trends Food Sci. Technol,20, 557-56.

Delalieux, S., Vanaardt, J., Keulemans, W., Schrevens, E., \& Coppin, P. (2007). Detection of biotic stress (Venturia inaequalis) in apple trees using hyperspectral data: Non-parametric statistical approaches and physiological implications. European Journal of Agronomy, 27 (1), $130-143$.

Espinoza, A., Vega, C., Medina, K., Schlauch, G., Cramer, P., \& Arce-Johnson. (2007). Gene expression associated with compatible viral diseases in grapevine cultivars, Funct. Integr. Genomics, 7, 95-110. 
Folimonova, S., \& Achor, D. (2010). Early Events of Citrus Greening (Huanglongbing) Disease Development at the Ultrastructural Level. The American Phytopathological Society, 100(9):949-58.

Food and Agriculture Organization Corporate Statistical Database (FAOSTAT). (2009). Food and agricultural commodities production: Countries by commodity: Oranges, 2009. Internet Available at: http://faostat.fao.org/SITE/339/default.aspx. Accessed 03/17/2014.

Food and Agriculture Organization of the United Nations. (2014). Available at: http://faostat.fao.org/site/567/DesktopDefault.aspx?PageID=567\#ancor, $\quad$ Accessed: $03 / 17 / 2014$

Fujikawa, T., \& Iwanami, T. (2012). Sensitive and robust detection of citrus greening (huanglongbing) bacterium "Candidatus Liberibacter asiaticus" by DNA amplification with new 16S rDNA specific primers. Molecular and Cellular Probes, 26,194-197.

Futch, S., Weingarten, S., \& Irey, M. (2009). Determining HLB infection levels using multiple survey methods in Florida citrus. In: Proceedings Florida State Horticultural Society (FSHS), 122, 152-158.

Garcia-Ruiz, F., Sankaran, S., Maja, J.M., Lee, W.S., Rasmussen, J., \& Ehsani, R. (2013). Comparison of two aerial imaging platforms for identification of Huanglongbing-infected. Computers and Electronics in Agriculture, 91, 106-115.

Gibly, A., Bonshtien, A., Balaji, V., Debbie, P., Martin, G.B., \& Sessa, G. (2004). Identification and expression profiling of tomato genes differentially regulated during a resistance response to Xanthomonas campestris pv. Vesicatoria. Mol. Plant Microb. Interact., $17,1212-1222$. 
Gibney, M.J., Walsh, M., Brennan, L., Roche, H.M., German, B., \& Ommen, B.V. (2005). Metabolomics in human nutrition: opportunities and challenges. Am. J. Clin.Nutr., 82, 497503.

Gonzalez, P., Achor, D., \& Albrigo, G., (2009). Anatomical distribution of abnormally high levels of starch in HLB-affected Valencia orange trees. Physiological and Molecular Plant Pathology, 74, 76-83.

Gottwald, T.R. (2010). Current epidemiological understanding of citrus Huanglongbing. Annu. Rev. Phytopathol, 48, 119-139.

Hansen, A.K., Trumble, J.T., Stouthamer, R., \& Paine, T.D. (2008). New Huanglongbing (Hlb) Candidatus species, “Ca. Liberibacter psyllaurous”, found to infect tomato and potato is vectored by the psyllid Bactericerca cockerelli (Sulc). Applied and Environmental Microbiology, 74 (18), 5862-5865.

Hawkins, S.A., Park, B., Poole, G.H., Gottwald, T., Windham, W.R., \& Lawrence, K.C. (2010). Detection of citrus Huanglongbing by Fourier Transform infrared-Attenuated total reflection (FTIR-ATR) spectroscopy. J. Appl. Spectrosc, 64,100-103.

Hung, T., Wu, M. \& Su, H. (1999). Detection of fastidious bacteria causing citrus greening disease by nonradioactive DNA probes. Ann phytopathol Soc. Jpn, 65:140-146.

Jagoueix, S., Bové, J.M., \& Garnier, M. (1996). PCR detection of the two 'Candidatus' Liberobacter species associated with greening disease of citrus. Mol Cell Probes, 10, 43-50.

Kaneko, H., Kawana, T., Fukushima, E., \& Suzutani, T. (2007). Tolerance of loop-mediated isothermal amplification to a culture medium and biological substances. J. Biochem. Biophys. Methods, 70(3):499-50L. 
Kim, J., \& and Wang, N. (2009). Characterization of copy numbers of $16 \mathrm{~S}$ rDNA and $16 \mathrm{~S}$ rRNA of Candidatus Liberibacter asiaticus and the implication in detection in planta using quantitative PCR. Biomedcentral Research Notes, 2:37. doi:10.1186/1756-0500-2-37.

Kogenaru, S., Yan, Q., Riera, N., Roper, M.C., Deng, X., Ebert, T.A., Rogers, M., Irey, M, Pietersen, G., Rush, C.M., \& Wang, N. (2014). Repertoire of novel sequence signatures for the detection of Candidatus Liberibacter Asiatic us by quantitative real-time PCR. Biomedcentral Microbiology, 14:39.

Lafleche, D., \& Bové, J.M. (1970). Structures de type mycoplasme dans les feuilles d'orangers atteints de la maladie du greening. CR Acad Sci Paris, 270, 1915-7.

Li W., Hartung, J. S., Levy, L., (2006). Quantitative real-time PCR for detection and identification of Candidatus Liberibacter species associated with citrus huanglongbing. Journal of Microbiological Methods 66 (2006) 104-115.

Li, W., Hartung, J.S., \& Levy, L. (2006). Quantitative real-time PCR for detection and identification of Candidatus Liberibacter species associated with citrus huanglongbing. Journal of Microbiological Methods, 66, 104-115.

Li, W., Levy, L., \& Hartung, J.S. (2009). Quantitative distribution of 'Candidatus Liberibacter asiaticus' in citrus plants with citrus huanglongbing. Phytopathology, 99, 13944.

Li,Q., Chen, F., Sun, L., Zhang ～，Z., Yang, Y. \& He, Z. (2006). Expression profiling of rice genes in early defense responses to blast and bacterial blight pathogens using cDNA microarray. Physiol. Mol. Plant Pathol, 68, 51-60.

Lin, H., Chen, C., Doddapaneni, H., Duan, Y., Civerolo, E.L., Bai, X., \& Zhao. X. (2010). A new diagnostic system for ultra-sensitive and specific detection and quantification of 
Candidatus Liberibacter asiaticus, the bacterium associated with citrus Huanglongbing. Journal of Microbiological Methods, 81, 17-25.

Mishra, A., Karimi, D., Ehsani, R., \& Albrigo, G. (2011). Evaluation of an active optical sensor for detection of Huanglongbing (HLB) disease. Bio systems engineering, 110, 302 309.

Morgan, J.K., Zhou, L., Li, W., Shatters, R.G., Keremane, M., \& Duan, Y. (2012). Improved real-time PCR detection of 'Candidatus Liberibacter asiaticus' from citrus and psyllid hosts by targeting the intragenic tandem-repeats of its prophage genes. Molecular and Cellular Probes, 26, 90-98.

Nagamine, K., Hase, T., \& Notomi, T. (2002). Accelerated reaction by loop-mediated isothermal amplification using loop primers. Mol Cell Probes, 16(3):223-229.

Nageswara-Rao, M., Irey, M., Garnsey, S., \& Gowda, S. (2013). Candidate gene markers for Candidatus Liberibacter asiaticus for detecting citrus greening disease. J. Biosci. 38(2), 229237.

Naidu, R.A., Perry, E.M., Pierce, F.J., \& Mekuria, T. (2009). The potential of spectral reflectance technique for the detection of Grapevine leafroll-associated virus-3 in two redberried wine grape cultivars. Computers and Electronics in Agriculture, 66 (1), 38-45.

Notomi, T., Okayama, H., Masubuchi, H., Yonekawa, T., Watanabe, K., Amino, N., \& Hase, T. (2000). Loop-mediated isothermal amplification of DNA. Nucleic Acids Res, 28(12):E63.

Panthee, D.R., Yuan, J.S., Wright, D.L., Marois, J.J., Mailhot, D., \& Stewart Jr.C.N. (2007). Gene expression analysis in soybean in response to the causal agent of Asian soybean rust (Phakopsora pachyrhizi Sydow) in an early growth stage, Funct. Integr. Genomics, 7, 291301. 
Peluffo, L., Lia,V., Troglia, C., Maringolo, C., Norma, P., Escande, A., Hopp, H.E., Lytovchenko, A, Fernie, A.R., Heinz, R., \& Carrari, F. (2010). Metabolic profiles of sunflower genotypes with contrasting response to Sclerotinia sclerotiorum infection. Phytochemistry, 71,70-80.

Pereira, F.M.V., \& Milori, D.M.B.P., (2010). Investigation of the stages of citrus greening disease using micro synchrotron radiation X-ray fluorescence in association with chemometric tools. Journal of Analytical Atomic Spectrometry, 25 (3), 351- 355.

Pereira, F.M.V., Milori, D.M.B.P., Pereira-Filho, E.R., Venâncio, A.L., Russo, M.S.T., Cardinali, M.C.B., Martins, P.K., \& Freitas-Astúa, J. (2011). Laser-induced fluorescence imaging method to monitor citrus greening disease. Computers and Electronics in Agriculture, 79, 90-93.

Pourreza, A., Lee, W. S., Ehsani, R., Schueller J. K., Raveh, E. (2015) An optimum method for real-time in-field detection of Huanglongbing disease using a visión sensor. Compueters and Electronics in Agriculture. 110(2015)221-232.

Pourreza, A., Lee, W.S., Raveh, E., Ehsani, R., Etxeberria E. (2014) Citrus Huanglongbin detection using narrow-band imaging and polarized illumination. American Society of Agricultural and Biological Engineers. ISSN 2151-0032 DOI 10.13031/trans.57.10147. Vol. 57(1): 259-272.

Purcell, D.E., O’ Shea, M.G., Johnson, \& R.A., Kokot, S. (2009). Near-infrared spectroscopy for the prediction of disease rating for Fiji leaf gall in sugarcane clones. Applied Spectroscopy, 63 (4), 450-457.

Qureshi, J.A., \& Stansly, P.A. (2009). Exclusion techniques reveal significant biotic mortality suffered by Asian citrus psyllid Diaphorina citri (Hemiptera: Psyllidae) populations in Florida citrus. Biological Control 50, 129-13. 
Rigano, L., Malamud, F., Orce, I., Filippone, M., Marano, M., Amaral, A.M., Castagnaro, A.; \& Vojnov, A. (2014). Rapid and sensitive detection of Candidatus Liberibacter asiaticus by loop mediated isothermal amplification combined with a lateral flow dipstick. Biomedcentral Microbiology, 14:86.

Sankaran, S. \& Ehsani, R. (2011). Visible-near infrared spectroscopy based citrus greening detection: Evaluation of spectral feature extraction techniques. Crop Protection, 30,15081513.

Sankaran, S., Mishra, A., Ehsani, R., \& Davis, C. (2010). A review of advanced techniques for detecting plant diseases. Computers and Electronics in Agriculture, 72,1-13.

Shokrollah, H., Abdullah, T.L., Sijam, K., \& Abdullah, S.N.A. (2011). Potential use of selected citrus rootstocks and interstocks against HLB disease in Malaysia. Crop Protection, $30,521-525$.

Teixeira D.C., Danet, J. L., Eveillard, S., Martins, E. C., Junior, W. C., Yamamoto, P. T., Lopes, S., Bassanezi, R. B., Ayres, A. J., Saillard, C., Bove, J. M.. Citrus huanglongbing in Sa o Paulo State, Brazil: PCR detection of the 'Candidatus' Liberibacter species associated with the disease. Molecular and Cellular Probes 19 (2005) 173-179.

Teixeira, T.A.D.C., Danet, J.L., Eveillard, S., Martins, E.C., Junior, W.C.J., Yamamoto, P. T., Lopes, S.A., Bassanezi, R.B., Ayres, A.J., Saillard, C., \& Bové J.M. (2005). Citrus huanglongbing in São Paulo State, Brazil: PCR detection of the 'Candidatus' Liberibacter species associated with the disease. Molecular and Cellular Probes, 19,173-179.

Teixeira, D., Dane, J.L., Eveillard, S., Martins, E.C., De Jesus, Jr. W.C., \& Yamamoto, P.T. (2005). Citrus huanglongbing in São Paulo State, Brazil: PCR 149 detection of the “Candidatus" Liberibacter species associated with the disease. Mol Cell Probes, 9:173-9. 
Teixeira, D.C., Saillard, C., Couture, C., Martins, E.C., Wulff, N.A., Eveillard-Jagoueix, S., Yamamoto, P.T., Ayres, A.J., \& M. Bové, J.M. (2008). Distribution and quantification of Candidatus Liberibacter americanus, agent of huanglongbing disease of citrus in São Paulo State, Brasil, in leaves of an affected sweet orange tree as determined by PCR. Molecular and Cellular Probes, 22,139-150.

Texeira, D.C., Ayres, A.J., Kitajima, E.W., Tanaka, F.A.O., Danet, J., \& Jagoueix-Eveillard, S. (2005). First report of a huanglongbing-like disease of Citrus in Sao Paulo State, Brazil, and association of a new Liberibacter species, 'Candidatus Liberibacter americanus', with the disease. American Phytopathological Society, 1, 89:107. 
Table 1 Nucleotide sequence of primers used for the amplification of Candidatus Liberibacter species by end point PCR and qPCR.

\begin{tabular}{|c|c|c|c|c|}
\hline HLB bacterium & Primer sequence $\left(5^{\prime}-3^{\prime}\right){ }^{*}$ & $\begin{array}{l}\text { DNA region } \\
\text { amplified }\end{array}$ & Type PCR & References \\
\hline \multirow{2}{*}{$\mathrm{Ca}$. Liberibacter } & $\begin{array}{l}\text { F: AGTCGAGCGAGTACGCAAGTACT } \\
\text { R: CAACTTAATGATGGCAAATATAG }\end{array}$ & 16S rDNA & $\begin{array}{l}\text { Conventional } \\
\text { PCR }\end{array}$ & $\begin{array}{l}\text { Nageswara-Rao et al., } \\
\text { 2013; Teixeira et al., } \\
2005^{\text {a }}\end{array}$ \\
\hline & $\begin{array}{l}\text { F: GAGCAGTACGCAAGTACTAG } \\
\text { Tp: AGACGGGTGAGTAACGCG } \\
\text { R: GCGTTATCCCGTAGAAAAAGGTAG }\end{array}$ & 16S rDNA & $\mathrm{qPCR}$ & $\begin{array}{l}\text { Kim, 2009; Li and } \\
\text { Levy, 2006; Li et al. } \\
2009\end{array}$ \\
\hline \multirow{3}{*}{$\begin{array}{l}\mathrm{Ca} \text {. Liberibacter } \\
\text { asiaticus }\end{array}$} & $\begin{array}{l}\text { F: CGCGTATGCAATACGAGCGGCA } \\
\text { R: GCCTCGCGACTTCGCAACCCAT }\end{array}$ & 16S rDNA & $\begin{array}{l}\text { Conventional } \\
\text { PCR }\end{array}$ & $\begin{array}{l}\text { Nageswara-Rao et al., } \\
\text { 2013; Teixeira et al., } \\
2005^{\text {a }}\end{array}$ \\
\hline & $\begin{array}{l}\text { F: TCGAGCGCGTATGCAATACG } \\
\text { Tp: AGACGGGTGAGTAACGCG } \\
\text { R: GCGTTATCCCGTAGAAAAAGGTAG }\end{array}$ & 16S rDNA & qPCR & $\begin{array}{l}\text { Kim, 2009; Li and } \\
\text { Levy, 2006; Li et al. } \\
2009\end{array}$ \\
\hline & $\begin{array}{l}\text { F: GCCGTTTTAACACAAAAGATGAATATC } \\
\text { Tp: ATAAATCAATTTGTTCTAGTTTACGAC } \\
\text { R: ACATCTTTCGTTTGAGTAGCTAGATCATTGA }\end{array}$ & $h y v_{I}$ and $h y v_{I I}$ & qPCR & Morgan et al. 2012 \\
\hline \multirow{2}{*}{$\mathrm{Ca}$. Liberibacter } & $\begin{array}{l}\text { F: GCGCGTATTTTATACGAGCGGCA } \\
\text { R: GCCTCGCGACTTCGCAACCCAT }\end{array}$ & 16S rDNA & $\begin{array}{l}\text { Conventional } \\
\text { PCR }\end{array}$ & $\begin{array}{l}\text { Nageswara-Rao et al., } \\
\text { 2013; Teixeira et al., } \\
2005^{\text {a }}\end{array}$ \\
\hline & $\begin{array}{l}\text { F: CGAGCGCGTATTTTATACGAGCG } \\
\text { Tp: AGACGGGTGAGTAACGCG } \\
\text { R: GCGTTATCCCGTAGAAAAAGGTAG }\end{array}$ & $16 \mathrm{~S}$ rDNA & $\mathrm{qPCR}$ & $\begin{array}{l}\text { Kim, 2009; Li and } \\
\text { Levy, 2006; Li et al. } \\
2009\end{array}$ \\
\hline
\end{tabular}

* F: Forward primer; R: Reverse primer. Tp: Taqman probe

**Intragenic tandem-repeats sequence. 